\title{
Comparison of positron emission tomography, cognition, and brain volume in Alzheimer's disease with and without severe abnormalities of white matter
}

\author{
C DeCarli, C L Grady, C M Clark, D A Katz, D R Brady, D G M Murphy, J V Haxby, \\ J A Salerno, J A Gillette, A Gonzalez-Aviles, S I Rapoport
}

Laboratory of

Neurosciences,

National Institute on

Aging

C DeCarli

C L Grady

C M Clark

D A Katz

D R Brady

D G M Murphy

J V Haxby

J A Salerno

J A Gillette

A Gonzalez-Aviles

$S$ I Rapoport

Epilepsy Research

Branch, National

Institute on

Neurological Disorders and Stroke, Bethesda,

MD, USA

$C$ DeCarli

Department of Neurology, University

of Pennsylvania,

Philadelphia, PA, USA

C M Clark

Office of the Clinical

Director, National

Institute on

Neurological Disorders

and Stroke, and

Laboratory of

Pathology, National

Cancer Institute,

Bethesda, MD, USA

D A Katz

Correspondence to:

Dr Charles DeCarli

Laboratory of Neurosciences,

Section on Brain Aging and

Dementia, National

Institutes of Health, Building

10, Room 6 C 414,

Bethesda, MD 20892, USA.

Received 13 December 1994

and in final revised form

16 August 1995

Accepted 7 September 1995

\section{Abstract}

Objectives-To examine cerebral metabolism, cognitive performance, and brain volumes in healthy controls and two groups of patients with probable Alzheimer's disease, one group with severe abnormalities of white matter $(D A T+)$ and the other group with none, or minimal abnormalities (DAT -).

Methods-Neuropsychological tests, CT, MRI, quantitative MRI, and PET studies were carried out to allow comparison between the DAT + and DAT - groups and the healthy controls.

Results-Compared with the healthy controls, both demented groups had significantly reduced global and regional cerebral metabolism, significant brain atrophy, and significantly lower scores on neuropsychological testing.

The DAT - patient group showed a pattern of parietal-temporal cerebral metabolic reductions and neuropsychological performance deficits typical of Alzheimer's disease. In addition, metabolism in the association neocortex (AD ratio) and measures of neuropsychological task performance were significantly correlated in the DAT - patient group.

Comparison of DAT + with DAT patients showed a significantly higher ratio of parietal to whole brain glucose utilisation for the DAT + group. Moreover, when comparing group $z$ score differences from the healthy controls, the DAT + group had, on average, smaller differences from controls in the frontal, parietal, and temporal regions than did the DAT - group. Discriminant analysis using metabolic ratios of the frontal, parietal, and temporal regions showed cerebral metabolic patterns to be significantly different among the DAT +, the DAT - , and the healthy controls. These differences were due primarily to relatively higher frontal, parietal, and temporal metabolic ratios in the DAT + group which resulted in discriminant scores for the DAT + group between the healthy controls and the DAT - group.

Group mean scores on tests of neuropsychological performance were not significantly different between the DAT - and DAT + patients. By contrast with the DAT - group, however, no significant correlations between the $A D$ ratio and any neuropsychological task were seen in the
DAT + group. Multiple regression analysis showed significant between group differences in the relation between the $A D$ ratio and neuropsychological scores on three tasks. The slopes of the relations between the $A D$ ratio and memory scores (memory and freedom from distractability deviation quotient of the Wechsler adult intelligence scale (WMDQ)) also were significantly different for the two groups.

Conclusions-Although multiple causes for abnormalities of white matter exist in patients with Alzheimer's disease, these data suggest that the presence of severe abnormalities of white matter indicate a second pathological process in the DAT + patients. The DAT - patients showed the parietal-temporal metabolic deficits and correlations between association neocortical metabolism and neuropsychological task performance typical of patients with Alzheimer's disease. By contrast, the DAT + group had a pattern of cerebral metabolism significantly different from healthy controls and DAT + patients, as well as no significant correlations between metabolism in the association neocortex and neuropsychological performance. These differences probably reflect the superimposed pathology of the abnormalities of white matter which may exert their affect through disruption of long corticocortical pathways.

$(尹$ Neurol Neurosurg Psychiatry 1996;60:158-167)

Keywords: dementia of the Alzheimer type; leukoaraiosis; magnetic resonance imaging; positron emission tomography

Abnormalities of cerebral white matter occur as part of normal aging, and are more prevalent in people with hypertension and cerebrovascular disease. ${ }^{12}$ Our understanding of how abnormalities of white matter affect cerebral structure and function, however, remains uncertain. In non-demented elderly subjects, most recent studies concur with the idea that abnormal white matter signals are associated with poorer neuropsychological test performance, ${ }^{3-6}$ brain atrophy, ${ }^{6-9}$ reduced cerebral blood flow ${ }^{10-12}$ and glucose utilisation, ${ }^{6}$ focal neurological signs, ${ }^{3}$ and a gait disorder. ${ }^{13}$ Examination of the same relations in patients with probable Alzheimer's disease has proved 
to be more difficult. The subtle neuropsychological abnormalities in non-demented patients with abnormal white matter ${ }^{3-6}$ may be overwhelmed by the Alzheimer's disease. Similarly, the brain atrophy and reduced blook flow and glucose metabolism accompanying abnormalities in white matter in nondemented subjects are small compared with the degree of brain atrophy and reductions in cerebral blood flow and metabolism caused by Alzheimer's disease. ${ }^{14}{ }^{15}$ Studies of the relation between abnormalities of white matter and dementia are further confounded when the presence of abnormal white matter is used as presumptive evidence for a vascular aetiology for the dementia. ${ }^{16} 17$

Despite methodological difficulties, differences between patients with Alzheimer's disease with and without abnormalities of white matter have been shown. After adjusting for duration of illness, demented patients with abnormalities of white matter have lower cognitive scores than demented patients without such abnormalities. ${ }^{18}$ The extent of abnormal white matter also significantly correlates with Blessed-Roth dementia scale scores. ${ }^{19}$ Patients with dementia with abnormalities of white matter express different clinical symptoms ${ }^{2021}$ and have lower regional white matter blood flow. ${ }^{11} 22$ However, it remains unclear if abnormalities of white matter are solely the consequence of Alzheimer's disease, or represent a different pathological process. ${ }^{23}$ Evidence that the abnormalities of white matter are unrelated to the basic pathology of Alzheimer's disease include the fact that they are more prevalent in late onset disease, ${ }^{2024}$ occur in cerebral amyloid angiopathy dementia without Alzheimer's disease, ${ }^{25}{ }^{26}$ and do not correlate with duration of dementia. ${ }^{27} 28$

We examined two groups of patients with probable Alzheimer's disease to explore the differences in brain structure and function in patients with Alzheimer's disease with severe abnormalities of white matter. Although these types of patients are uncommon, ${ }^{7232627}$ we made our comparison between patients with Alzheimer's disease with minimal or no abnormalities of white matter (DAT -) and patients with severe abnormalities of white matter $(\mathrm{DAT}+)$. This comparison is based on the hypothesis that the most extreme differences would best identify the role of the abnormalities of white matter, and the evidence that a threshold amount of abnormalities must be present to have an effect on cerebral structure and function. ${ }^{410}$ The DAT - group was selected to be comparable on measures of age, education, and severity of dementia with the $\mathrm{DAT}+$ group, and was contrasted with a third group of healthy control subjects on regional cerebral metabolism of glucose, neuropsychological test score, and regional brain volumes. Preliminary results have been published. ${ }^{29}$

Methods
SUBJECTS
Healthy controls

The healthy control subjects consisted of seven men and seven women. Each subject underwent rigorous medical, neurological, and laboratory screening. ${ }^{30}$ Subjects with medical illness, psychiatric disorders, history of head trauma, or substance misuse were excluded. No subject received medication in the two weeks before the evaluation.

\section{$D A T$ - patients}

The DAT - patient group consisted of eight men and six women selected with the same stringent health screening criteria as the healthy controls. For each patient, Alzheimer's disease was diagnosed as "probable" using NINCDS-ADRDA criteria. ${ }^{31}$ The degree of cognitive impairment was graded according to mini mental state examination (MMSE) scores $^{32}$ as mild (MMSE > 20), moderate (> 10 MMSE < 20), and severe (MMSE $<10)$. The DAT - patients were chosen from a larger group and were selected to be comparable with the DAT + group for age, education, severity of dementia, and duration of illness.

Five DAT - patients subsequently died. All met pathological criteria for definite Alzheimer's disease. ${ }^{34} 35$

\section{$D A T+$ patients}

The DAT + patient group consisted of six men and six women identified consecutively with severe abnormalities of white matter on brain imaging, and who otherwise met clinical criteria for probable Alzheimer's disease. ${ }^{34}$ Health screening differed from the healthy controls and DAT - patients in that seven of 12 had hypertension. Patients with stroke, either by history or on structural imaging were excluded. Alzheimer's disease was diagnosed in the same fashion as the DAT - group.

Five DAT + patients subsequently died. All met pathological criteria for definite Alzheimer's disease. ${ }^{34} 35$

\section{STUDY DESIGN}

All patients and controls participated as part of three separate, but concurrent, longitudinal studies at the Laboratory of Neurosciences, National Institute on Aging (NIA), National Institutes of Health. All patients and controls signed informed consent forms developed in accordance with NIH guidelines, and reviewed by the NIA Internal Review Board. For the demented patients, these studies required a brief inpatient stay, off all medications, during which time careful clinical evaluation, extended neuropsychological testing, structural brain imaging (MRI and CT), and PET were obtained.

RATING OF ABNORMALITIES OF WHITE MATTER ON BRAIN IMAGES

The presence of abnormalities of white matter was determined from either non-contrast CT, T2 weighted MRI, or both. Leukoaraiosis on non-contrast head CT was identified as present or absent by radiologists unaware of the clinical status of the subject and using the definition of Hachinski et al. ${ }^{36}$ Leukoaraiosis of moderate to severe degree was present on CT 


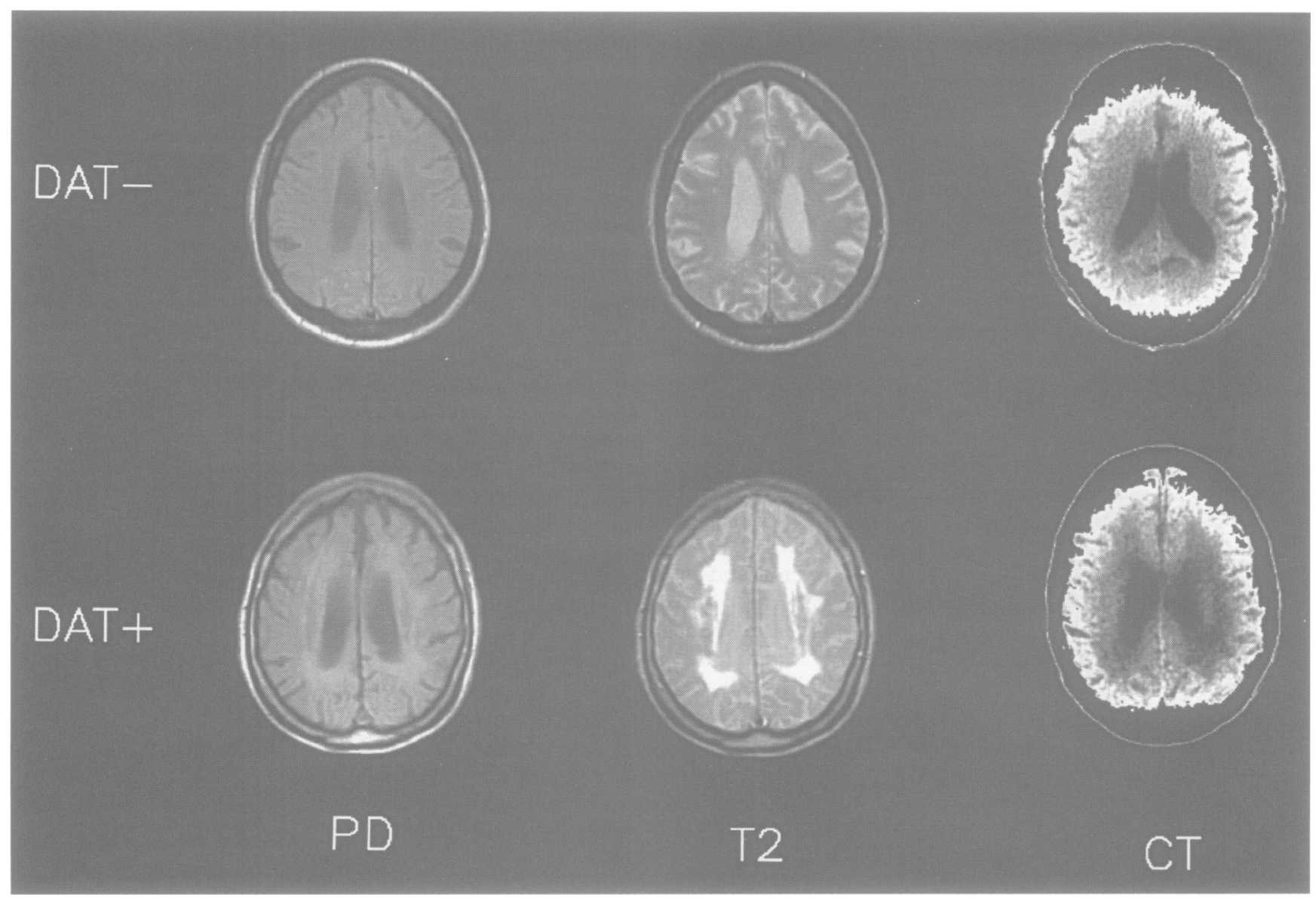

Figure 1 Examples of leukoencephalopathy as seen on $C T$ and $M R I$ images of $D A T-$ and $D A T+$ patients. CT and MRI images for the healthy control group were the same as the $D A T-$ group. $P D=$ first echo of double echo MR sequence and T2 second echo.

of each DAT + patient, but was absent from the CT of the DAT - patients and healthy controls. In addition, an MRI spin echo brain image was obtained for most of the demented patients and all healthy controls. We used the four point scale of Fazekas et $a l^{37}$ for rating white matter hyperintensities $(0=$ absent; 3 $=$ severe). Qualitative ratings of the healthy controls and DAT - patients did not exceed a rating of 1 for periventricular or deep white matter hyperintensities on T2 weighted images (TR 2000, TE 80). The DAT+ patients, however, had ratings of at least 3 for periventricular or deep white matter hyperintensities. Figure 1 is an example of the group differences in structural images between the $\mathrm{DAT}$ - and DAT + patients.

\section{NEUROPSYCHOLOGY}

The Wechsler adult intelligence scale (WAIS $^{38}$ ), Benton facial recognition test ${ }^{39}$, Boston naming test ${ }^{40}$, and the extended range drawing test ${ }^{41}$ were given to evaluate general intellectual, verbal, and visuospatial functions. Tests of immediate and delayed recall for stories and figures from the Wechsler memory scale were used as standard measures of visual and verbal memory. ${ }^{42}$ Frontal lobe executive function, thought to be preferentially affected by abnormalities of cerebral white matter, ${ }^{463}$ was measured with the Porteus maze, ${ }^{44}$ Stroop colour-word interference task, and trails part A and part B. ${ }^{45} 46$ Neuropsychological testing was attempted for all the patients with dementia, but one DAT + and one DAT - patient were unable to fully cooperate.

\section{QUANTITATIVE MRI}

Brain MRI was performed on a 0.5 Tesla scanner (Picker Instruments, Cleveland, $\mathrm{OH}$ ). Axial images were analysed using the proton density (TR 2000, TE 20) portion of a double echo sequence (TR 2000/20/80) according to previously published methods. ${ }^{478}$ Eighteen 7 mm thick contiguous slices were obtained from the foramen magnum to the vertex, parallel to an estimated orbitomeatal line. A region of interest analysis ${ }^{48}$ was applied to determine the volumes of the cerebral ventricles, and segmentation analysis ${ }^{47}$ to determine cerebral and hemispheric CSF and brain volumes. To correct for individual differences in head size on measures of brain volume, ${ }^{49}$ all statistical comparisons were performed on brain and CSF volumes calculated as a percentage of total intracranial volume. Five of the 25 demented patients were unable to cooperate enough to obtain MRIs of sufficient quality for quantification. These patients were more severely demented, and had a mean MMSE score of $7 \cdot 3$ (SD 8.5).

PET STUDIES

Brain PET was performed on a Scanditronix PC1024-7B tomograph (Uppsala, Sweden), a seven slice machine with a transverse resolu- 
Table 1 Comparison of demographic variables for $D A T-, D A T+$ patients and healthy controls

\begin{tabular}{llll}
\hline & $D A T-$ & $D A T+$ & Controls \\
\hline No & 14 & 12 & 14 \\
Sex (M/F) & $8 / 6$ & $6 / 6$ & $7 / 7$ \\
Age (y) & $71 \cdot 6(8 \cdot 0)$ & $75 \cdot 4(6 \cdot 0)$ & $65 \cdot 4(7 \cdot 0)^{\star}$ \\
Education (y) & $(61-86)$ & $(66-83)$ & $(58-81)$ \\
Duration of dementia (y) & $(15 \cdot 5(2 \cdot 7)$ & $13 \cdot 3(4 \cdot 4)$ & $15 \cdot 1(2 \cdot 2)$ \\
MMSE & $(11-19)$ & $(5-19)$ & $(12-20)$ \\
Ischaemic scales & $(2-14)$ & $5 \cdot 5(2 \cdot 3)$ & - \\
& $12 \cdot 8(8 \cdot 1)$ & $12 \cdot 0(9 \cdot 9)$ & $29 \cdot 6(1 \cdot 0)^{\star}$ \\
Hypertension & $(0-25)$ & $(0-25)$ & $(28-30)$ \\
\hline
\end{tabular}

Values are mean (SD) and (range) beneath.

$\star \mathrm{DAT}-$ and DAT + are significantly different from healthy controls.

†DAT + is significantly different from DAT -

FDAT + is significantly different from controls and DAT -

From Hachinski et al. ${ }^{33}$

tion of $6 \mathrm{~mm}$ and an axial resolution of $10 \mathrm{~mm}$. Catheters were placed in a radial artery for drawing blood samples and in an antecubital vein for injecting the isotope. Subjects were placed in the scanner, with their eyes covered, ears occluded, and heads held in place by a thermoplastic mask. Transmission scans were obtained for attenuation correction, and then a bolus of $5 \mathrm{mCi}$ of ${ }^{18} \mathrm{~F}-2$ deoxy-D-glucose was injected intravenously. The emission scans were begun after a 45 minute uptake period. Two interleaved scans were obtained parallel to and $10-100 \mathrm{~mm}$ above the inferior orbitomeatal line, resulting in a total of 14 slices. Arterial blood samples were drawn throughout the procedure for measurement of plasma radioactivity and glucose concentration. Regional cerebral metabolic rates for glucose were calculated from a modification ${ }^{50}$ of the operational equation of Sokoloff et al. ${ }^{51}$

PET DATA ANALYSIS

Data from PET were analysed with a template of circular regions of interest $8 \mathrm{~mm}$ in diameter $\left(48 \mathrm{~mm}^{2}\right)$. The regions of interest were spaced evenly throughout the cortical and subcortical regions. Regional metabolic rates were obtained by averaging values in the circular regions that fell within anatomically recognised areas, such as the superior parietal or superior temporal areas. ${ }^{52}$ Both absolute regional cerebral metabolic rates for glucose (rCMRglc) and ratio measures of rCMRglc to whole brain metabolic rates for glucose (rCMRglc/CMRglc) were used for group comparisons.

We also calculated a metabolic ratio $(\mathrm{AD}$

Table 2 Regional comparison of rCMRglc/CMRglc for controls, DAT- , and DAT+ patients

\begin{tabular}{|c|c|c|c|}
\hline Region & Controls & $D A T-$ & $D A T+$ \\
\hline Whole brain & $6.27(1 \cdot 13)^{\mathrm{a}}$ & $4.56(1.01)^{b}$ & $4.32(0.87)^{b}$ \\
\hline $\begin{array}{l}\text { Frontal lobe } \\
\text { Parietal lobe } \\
\text { Temporal lobe } \\
\text { Sensory motor cortex } \\
\text { Calcarine cortex } \\
\text { Basal ganglia } \\
\text { White matter } \\
\text { Cerebellum } \\
\text { Brain stem }\end{array}$ & $\begin{array}{l}1.30(0.05) \\
1.34(0.06)^{\mathrm{a}} \\
1.15(0.06)^{2} \\
1.33(0.05)^{\mathrm{a}} \\
1.32(0.07)^{\mathrm{a}} \\
1.49(0.13)^{\mathrm{a}} \\
0.49(0.14) \\
1.12(0.10)^{\mathrm{a}} \\
0.88(0.15)^{\mathrm{a}}\end{array}$ & $\begin{array}{l}1 \cdot 27(0.11) \\
1 \cdot 14(0 \cdot 11)^{\mathrm{b}} \\
1.07(0 \cdot 15)^{\mathrm{b}} \\
1.44(0 \cdot 16)^{\mathrm{b}} \\
1.50(0 \cdot 19)^{\mathrm{b}} \\
1.71(0 \cdot 25)^{\mathrm{b}} \\
0.62(0 \cdot 19) \\
1.38(0 \cdot 21)^{\mathrm{b}} \\
1 \cdot 14(0 \cdot 21)^{\mathrm{b}}\end{array}$ & 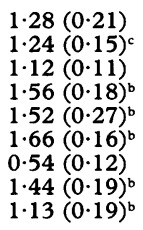 \\
\hline
\end{tabular}

Values are mean (SD); values with different superscripts are significantly different from each other after correcting for multiple comparisons. ratio) in which the numerator was the average of the association neocortical regions (frontal, temporal, and parietal) and the denominator was the average of primary sensory and motor, basal ganglia, and cerebellar regions. Previous studies $^{53}$ have shown that this ratio is highly correlated with the cognitive deficits of patients with Alzheimer's disease.

\section{STATISTICAL ANALYSES}

Group differences in dichotomous variables were analysed using a $\chi^{2}$ test after continuity adjustment or Fisher's exact test. ${ }^{54}$ Age, education, duration of illness, neuropsychological test scores, and quantitative MRI volumes were compared between the DAT - and DAT + groups with Student's $t$ test. The relations between quantitative MRI and PET measures and neuropsychological performance scores were tested with Pearson correlations. Further examination of the relation between the $A D$ ratio and neuropsychological test scores was performed with multiple regression analysis. ${ }^{55}$ Between group differences in rCMRglc were compared by three way analysis of variance (ANOVA) with post hoc mean comparisons. ${ }^{54}$ Patterns of cerebral metabolism were compared between the healthy controls, DAT +, and DAT - groups with discriminant analysis. Discriminant function scores were also compared with three way ANOVA and post hoc mean comparison.

\section{Results}

\section{DEMOGRAPHICS}

Table 1 summarises the group demographics. The healthy controls were significantly younger than the dementia groups. The dementia groups did not differ significantly on age, duration of illness, years of education, or mean MMSE. The DAT + group had a significantly higher prevalence of hypertension $\left(\chi^{2}\right.$ $=9.8, P<0.002)$, and significantly higher ischaemic scale scores $(P<0.05)$.

\section{PET STUDIES}

The rCMRglc and CMRglc values were significantly greater in the healthy controls compared with the demented patients for all brain regions except the cerebellum and cerebral white matter. No significant differences in rCMRglc between the DAT - and DAT + patients were found (data not shown). When cerebral metabolism was assessed as the ratio to whole brain metabolism (rCMRglc/ CMRglc), as summarised in table 2 however, DAT + patients had significantly greater parietal ratios than the DAT - patients.

To further examine regional metabolic differences between the DAT + and DAT groups, regional cerebral metabolism was converted into $z$ score differences from healthy controls. To calculate each $z$ score, the healthy control group mean rCMRglc was subtracted from each patient's rCMRglc and divided by the healthy control group rCMRglc SD. Figure 2 shows the mean $z$ score differences from controls in rCMRglc/CMRglc. The DAT - group shows the typical frontal, tem- 


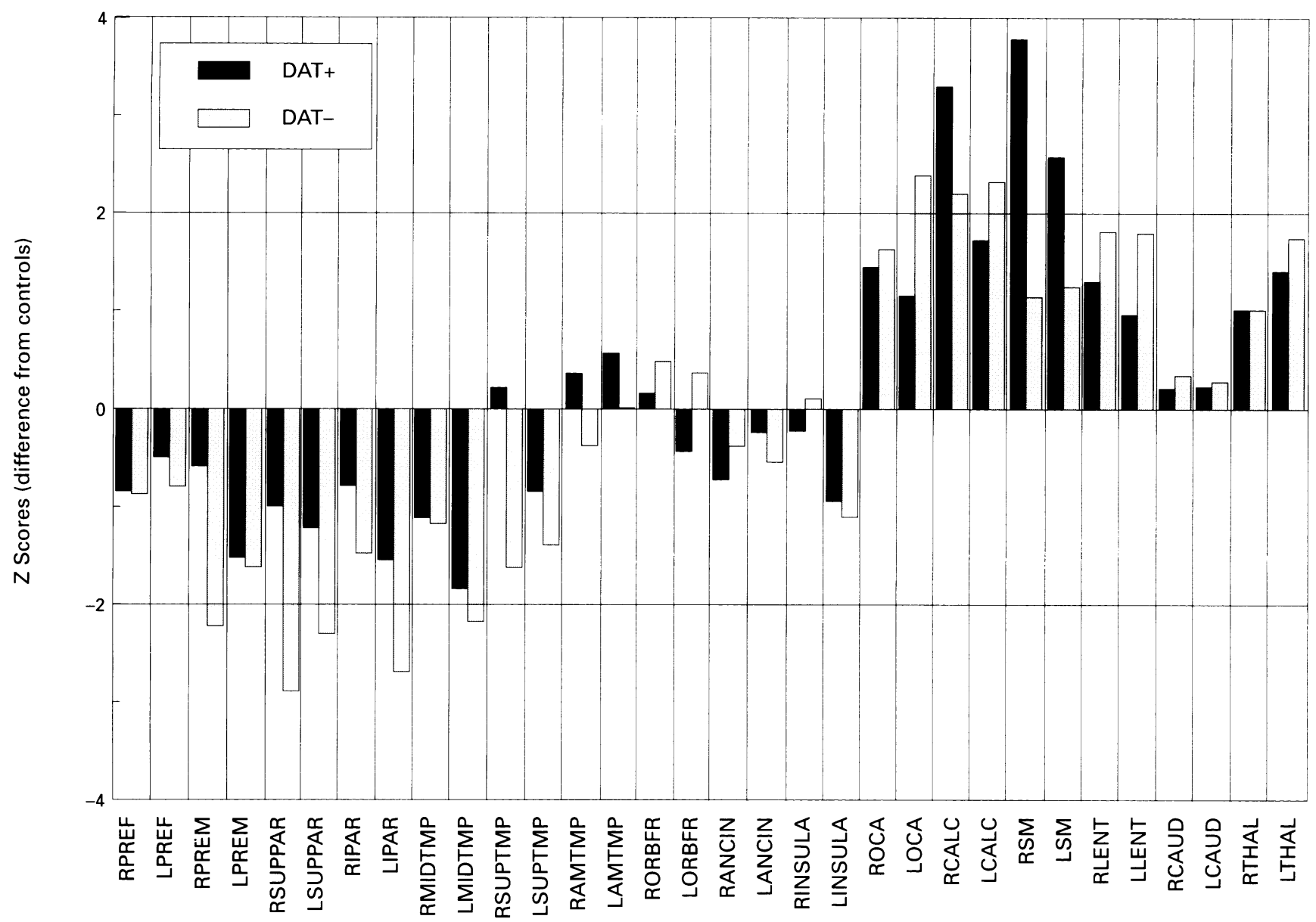

Figure 2 Regional group mean $z$ score differences from healthy controls across 32 sampled regions. See text for explanation of regions of interest. The black horizontal lines indicate $z$ scores of 2 and -2 . PREF = prefrontal cortex; PREM = premotor cortex; SUPPAR = superior parietal cortex; IPAR $=$ inferior parietal cortex; $M I D T M P=$ middle and inferior temporal cortices; SUPTMP $=$ superior temporal cortex; $A M T M P=$ amygdaloid; anterior medial hippocampal and parahippocampal cortices; ORBFR = orbital frontal cortex; $A N C I N=$ anterior cingulate; OCA $=B$ Bodmann areas 18 and 19; CALC = calcarine cortex; SM = precentral and postcentral gyri LENT = lenticular nuclei; CAUD = caudate; THAL = thalamus. L = left, $R=$ right.

poral, parietal pattern of hypometabolism thought to be characteristic of Alzheimer's disease, whereas the DAT + group shows a relative sparing of metabolism in these areas.

Given these between group differences, discriminant analysis was performed using the frontal, parietal, and temporal metabolic ratios (listed as RPREF to LSUPTMP in fig 2). We chose discriminant analysis as this statistical method allows for estimation of the linear combination of all the regions on group differences. We also included the healthy control group in this analysis to show how the two dementia groups differ, not only from each other, but in relation to subjects without dementia (are the two dementia groups different because one group looks more like the healthy controls, or is the pattern of cerebral metabolism uniquely different among each of the dementia groups and controls?). Because the discriminant analysis was performed between three groups, two discriminant functions are generated and subject classification is based on a weighted combination of the scores along each function. Subject classification based on the combined information of the two discriminant functions was significant (Wilks' lambda $\left.=0.24, \quad F_{(24,48)}=2 \cdot 06, \quad P=0.017\right)$ and completely accurate for all groups. That is, each subject used to derive the discriminant function was correctly classified as DAT + , DAT - , or healthy control.

The first discriminant function explained $81 \%$ of the between group differences $(\mathrm{P}<$ $0.02)$. Individual discriminant scores correlated significantly $(P<0.01)$ with the right and left frontal premotor, right and left superior and inferior parietal, and right and left middle temporal metabolic ratios, regions preferentially involved in Alzheimer's disease. ${ }^{1+11}$ The group discriminant score means were 1.57 (SD 0.85 ) for the healthy controls, -0.17 (SD 0.97) for the DAT + patients, and $-1.55(1.55)$ for the DAT - patients. Analysis of variance showed a significant group effect of discriminant scores $\left(F_{(2,35)}=\right.$ $33, \mathrm{P}<0.0001)$. On post hoc analysis, each group was significantly different from the others. The DAT + patients, therefore, had a significantly different pattern of glucose utilisation with generally higher metabolic ratios than the DAT - patients, but generally lower metabolic ratios than the healthy controls.

The second discriminant function explained the remaining variance, but was not significant $\left(F_{(11,25)}=0.98, P=0.49\right)$. The group discriminant score means along this function, however, were $0.34(\mathrm{SD} 0.86)$ for the healthy controls, 0.46 (SD 1.17) for the DAT - 
Figure 3 Relation on the first and second discriminant functions for each group. between discriminant scores

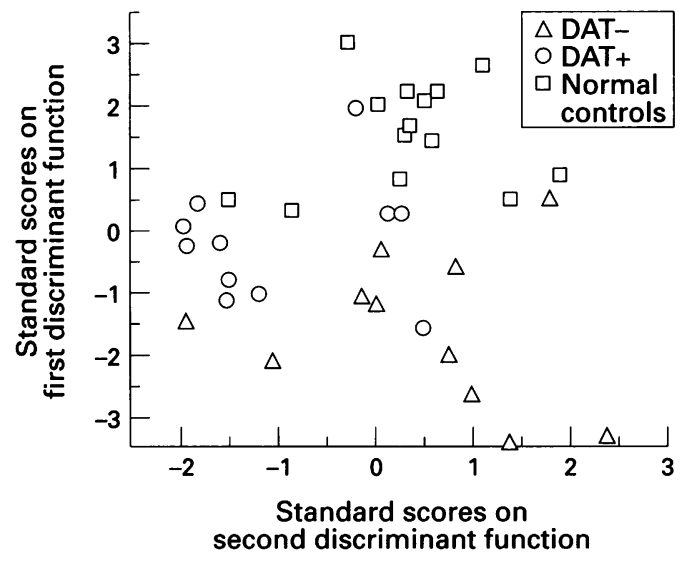

Table 3 Neuropsychological scores $D A T-v D A T+$ patients

\begin{tabular}{llcc}
\hline Neuropsychological task & Controls & $D A T-$ & $D A T+$ \\
\hline Full scale IQ & $124 \cdot 4(11 \cdot 9)$ & $87 \cdot 8(19)$ & $83 \cdot 9(23)$ \\
Verbal IQ & $125 \cdot 2(12 \cdot 6)$ & $92 \cdot 0(20)$ & $88 \cdot 4(28)$ \\
Performance IQ & $119 \cdot 9(11 \cdot 9)$ & $83 \cdot 8(22)$ & $79 \cdot 2(17)$ \\
Wechsler immediate verbal memory & $10(2 \cdot 6)$ & $4 \cdot 9(4 \cdot 7)$ & $3.5(4 \cdot 4)$ \\
Wechsler delayed verbal memory & $8 \cdot 2(2 \cdot 8)$ & $1 \cdot 8(4 \cdot 8)$ & $0 \cdot 9(2 \cdot 2)$ \\
Wechsler immediate visual memory & $2 \cdot 1(1 \cdot 2)$ & $1 \cdot 3(1 \cdot 5)$ & $0 \cdot 8(1 \cdot 5)$ \\
Wechsler delayed visual memory & $8 \cdot 0(3 \cdot 8)$ & $0 \cdot 08(0 \cdot 3)$ & $0 \cdot 09(0 \cdot 3)$ \\
Extended range drawing & $18 \cdot 3(3 \cdot 2)$ & $11 \cdot 0(7 \cdot 0)$ & $11 \cdot 3(6 \cdot 1)$ \\
Benton facial recognition & $45 \cdot 8(3 \cdot 0)$ & $36 \cdot 8(4 \cdot 9)$ & $27 \cdot 0(14)^{\star}$ \\
Boston naming & $76 \cdot 0(8 \cdot 1)$ & $36 \cdot 6(27)$ & $27 \cdot 0(27)$ \\
Porteus maze & $15 \cdot 2(2 \cdot 1)$ & $6 \cdot 4(4 \cdot 5)$ & $5 \cdot 6(5 \cdot 3)$ \\
Stroop interference & $66 \cdot 4(11 \cdot 5)$ & $8 \cdot 5(6 \cdot 4)$ & $3 \cdot 7(4 \cdot 3)$ \\
Trails A & $41(20)$ & $178(103)$ & $242(130)$ \\
Trails B & $86(40)$ & $437(105)$ & $437(13)$ \\
\hline
\end{tabular}

Values are mean (SD); the dementia group means for each nuropsychological score differed significantly from health controls.

$\star \mathrm{DAT}+$ differs from DAT $-(\mathbf{P}<0.05)$

patients, and $-0.98(\mathrm{SD} 0.95)$ for the DAT + patients.

Examination of the biterritorial map of standard scores on the first and second discriminant functions (fig 3) disclosed three distinct clusters consistent with a unique metabolic pattern for each group. The healthy controls clustered in the positive range of the first function, but near zero in the second function. The DAT - group clustered in the negative range on the first function and along the entire axis on the second function. The DAT + group, however, clustered near zero on the first function but negatively on the second function in the area not occupied by either the controls or DAT - groups.

Because the discriminant analysis was performed on many regions, we also examined which regions had the greatest independent effect on the group differences by using stepwise discrimination. Nearly all the between group differences were explained by four variables. The left inferior parietal region explained $20 \%$ of the variance, the right frontal premotor region $30 \%$, the left superior parietal region $11 \%$, and the left middle temporal region explained the remaining error. The regions found by the stepwise discriminant function also significantly discriminated between groups $(P<0.05)$, and similarly to the previous discriminant function, the mean discriminant scores were negative for the DAT - group, near zero for the DAT + group, and positive for the healthy controls.

\section{NEUROPSYCHOLOGY}

The two dementia groups performed worse ( $P$ $<0.001)$ than the healthy controls on each of the neuropsychological tests. The DAT+ patients performed worse, on average, than the DAT - patients, but this difference was significant only for Benton facial recognition test scores (table 3).

Patterns of cerebral metabolism have been associated with patterns of cognitive performance in patients with Alzheimer's disease. ${ }^{145253}$ If abnormalities of white matter alter cerebral metabolism and cognitive performance in healthy subjects, ${ }^{6}$ we would expect their presence to have a similar effect in the DAT + patients. Using the metabolic ratio (AD ratio) described by Mielke et al,,$^{53}$ we examined the relation between cerebral glucose metabolism and severity of dementia for the DAT - and $\mathrm{DAT}+$ groups. The mean $\mathrm{AD}$ ratio scores were 0.83 (SD 0.13) for the DAT - group and $0.86(\mathrm{SD} 0 \cdot 10)$ for the DAT + group. Table 4 shows the zero order correlations between the $\mathrm{AD}$ ratio and various scales of the WAIS and the MMSE.

Significant and large correlations between the $\mathrm{AD}$ ratio and four of the scale scores of the WAIS and the MMSE were found for the DAT - patients, whereas no relation was significant for the DAT + patients. As small group size and high variance could have contributed to the lack of significant correlations between the $A D$ ratio and neuropsychological test scores in the DAT + group, we performed a multiregression analysis of the relation between the neuropsychological test scores and $\mathrm{AD}$ ratio to assess whether this relation was the same for the two demented groups. All multiple regression models were statistically significant $(P<0.05)$. In three models where MMSE, WAIS verbal deviation quotient (WVDQ), and WAIS memory and freedom from distractability deviation quotient (WMDQ) were used to predict the $\mathrm{AD}$ ratio, the group effect was significant. In three other models where WAIS full scale IQ (WFSIQ), WAIS verbal IQ (WVIQ), and WAIS perfor-

Table 4 Correlation of neuropsychological scores with $A D$ ratio for $D A T-v D A T+$ patients

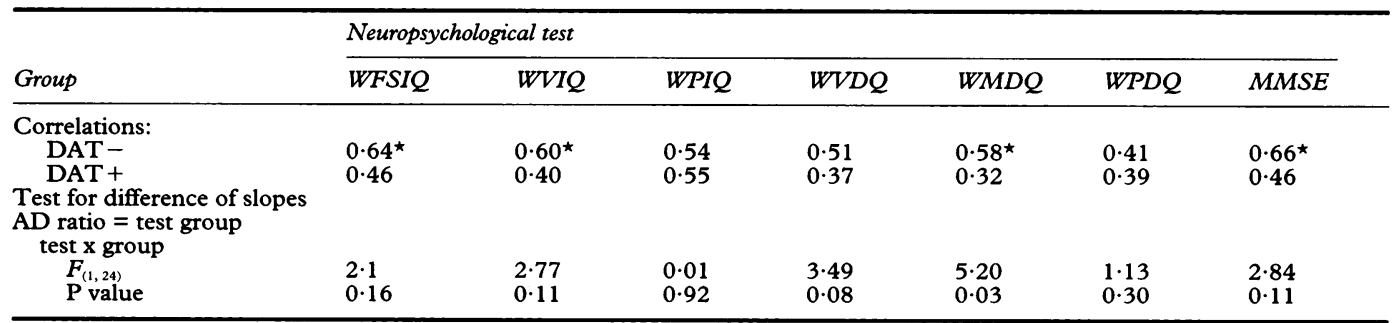

«Significant correlation.

For abbreviations see text. 
Figure 4 Relation between the $A D$ ratio and scores on the WAIS memory quotient subscale.

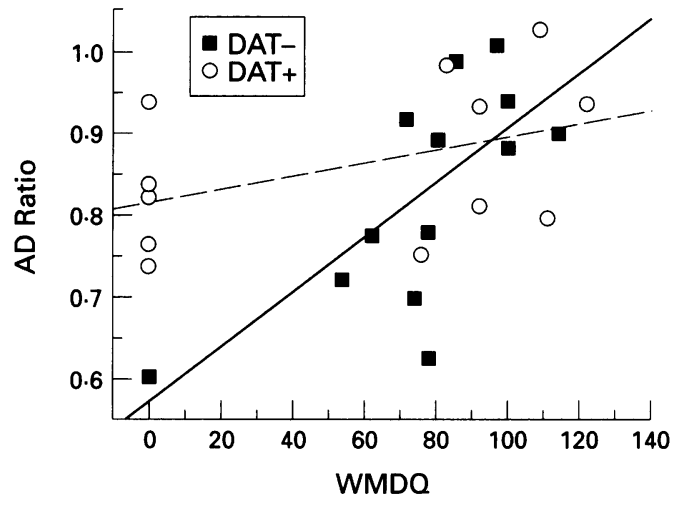

mance deviation quotient (WPDQ) were used to predict the $\mathrm{AD}$ ratio, the group effect showed a trend toward significance with $\mathrm{P}$ values $\leqslant 0 \cdot 10$. Moreover, in the model, when WMDQ was used to predict the $\mathrm{AD}$ ratio, the interaction term between group and WMDQ was significant, and in three other models, where WVDQ, WVIQ, and MMSE were used as predictors the interaction term had a $P$ value $\leqslant 0 \cdot 11$. Figure 4 shows the relation between $A D$ ratios and WMDQ scores. The $\mathrm{AD}$ ratio was greater for the $\mathrm{DAT}+$ group (significant group effect, $F_{(1,24)}=7 \cdot 4, \mathrm{P}<$ $0.5)$, and the slopes of group regression lines were significantly different (significant interaction,

$\left.F_{(1,24)}=5 \cdot 2, \mathrm{p}<0.05\right)$, indicating a different relation between the $A D$ ratio and WMDQ scores.

Age, years of education, and sex are also known to influence performance on neuropsychological tasks in healthy subjects. ${ }^{56}$ As between group differences on these variables could have influenced analysis of neuropsychological test scores between the DAT + and DAT - groups, we examined the predictive value of these variables on each neuropsychological task. None significantly predicted performance on any neuropsychological task.

\section{QUANTITATIVE MRI}

The two dementia groups had significantly smaller total brain and cerebral hemisphere volumes and significantly larger central and subarachnoid CSF volumes than healthy controls $(\mathrm{P}<0.01)$. Table 5 summarises the brain and CSF volumes for the DAT - and DAT + groups. No significant between group difference was found in either brain matter or CSF volumes. There was a significant correlation

Table 5 Regional brain and CSF volumes for $D A T-v D A T+$ patients

\begin{tabular}{|c|c|c|c|}
\hline Region & $\begin{array}{l}\text { Controls } \\
(14 / 14)\end{array}$ & $\begin{array}{l}D A T- \\
(11 / 14)\end{array}$ & $\begin{array}{l}D A T+ \\
(10 / 12)\end{array}$ \\
\hline $\begin{array}{l}\text { Total cranial volume } \\
\text { Cerebral brain volume } \\
\text { Right hemisphere brain volume } \\
\text { Left hemisphere brain volume } \\
\text { Total cerebral CSF } \\
\text { Right lateral ventricle } \\
\text { Left lateral ventricle } \\
\text { Third ventricle } \\
\text { Central CSF } \\
\text { Subarachnoid CSF }\end{array}$ & $\begin{array}{l}1219(150) \\
88 \cdot 2(3 \cdot 5) \\
43.5(1 \cdot 7) \\
43 \cdot 2(2 \cdot 2) \\
12.3(3 \cdot 0) \\
0.7(0.5) \\
0.7(0.5) \\
0 \cdot 10(0 \cdot 06) \\
1.5(1.0) \\
10.8(2 \cdot 7)\end{array}$ & $\begin{array}{l}1251(177) \\
80 \cdot 3(5 \cdot 2) \\
40 \cdot 4(3 \cdot 1) \\
39 \cdot 6(2 \cdot 4) \\
19 \cdot 7(5 \cdot 2) \\
1 \cdot 9(1 \cdot 1) \\
2 \cdot 1(1 \cdot 1) \\
0 \cdot 14(0 \cdot 10) \\
4 \cdot 2(2 \cdot 2) \\
15 \cdot 5(5 \cdot 2)\end{array}$ & $\begin{array}{c}1182(142) \\
79 \cdot 6(3 \cdot 7) \\
40 \cdot 1(1 \cdot 4) \\
39 \cdot 3(2 \cdot 7) \\
20 \cdot 0(3 \cdot 6) \\
2 \cdot 4(0 \cdot 8) \\
3 \cdot 0(1 \cdot 5) \\
0 \cdot 20(0 \cdot 07) \\
5 \cdot 7(2 \cdot 3) \\
14 \cdot 3(2 \cdot 3)\end{array}$ \\
\hline
\end{tabular}

Values are mean (SD)

The dementia group means for each quantitative MRI measure differed significantly from healthy controls. There were no significant differences between DAT + and DAT - scores. between central CSF volumes and MMSE for the demented patients $(r=-0.49, \mathrm{P}<0.03)$ which did not differ significantly between the DAT - group $(r=-0.37)$ and the DAT + group $(r=-0.54)$. Between group differences in the number of MRIs quantified did not seem to bias the results as there was neither a significant difference in the number of missing scans between the DAT - and DAT + groups $\left(\chi^{2}=0.9, \mathrm{P}>0.05\right)$, nor a significant difference in the MMSE of the patients having MRI (DAT - mean MMSE $=13.5(\mathrm{SD} 8 \cdot 6) ; \mathrm{DAT}+$ mean MMSE = $9 \cdot 6(\mathrm{SD} 9 \cdot 1) ; \mathrm{P}>0.05)$.

\section{Discussion}

Our results show that the presence of severe abnormalities of white matter in DAT+ patients significantly affected the pattern of resting cerebral glucose metabolism and significantly altered the relation between regional cerebral metabolism and WMDQ scores. Whereas DAT + patients scored lower than DAT - on neuropsychological tests, these differences were generally non-significant. Brain volumes were nearly identical for the two groups.

The findings of an altered pattern of cerebral metabolism and a significantly different relation between cerebral metabolism and WMDQ scores supports the notion that abnormalities of white matter in patients with $\mathrm{DAT}+$ reflect a pathophysiological process that is different from Alzheimer's disease. ${ }^{23} 24$ Most of our DAT + patients had hypertension, however. As hypertension is associated with brain atrophy ${ }^{57} 58$ and a higher prevalence of abnormalities of white matter, ${ }^{127}$ it is possible that the differences in cerebral metabolism and the differences in the relation between cerebral metabolism and WMDQ scores could simply reflect the effect of hypertension on the brains of DAT + patients. Non-demented hypertensive patients without severe white matter changes have reduced cerebral metabolism compared with controls, but without significant reductions in neuropsychological performance. ${ }^{5859}$ The degree of reduced glucose utilisation is small, however, and maximal in the vascular watershed brain regions, a distribution different from the metabolic pattern of Alzheimer's disease. So, although hypertension may be causal to the abnormalities of white matter in the DAT + patients, it does not seem that the metabolic differences can be explained by the hypertension alone.

With regard to group mean differences in neuropsychological performance, our results are consistent with some, but not all, reports of neuropsychological testing in dementia with abnormalities of white matter. ${ }^{18-21}$ Our patients differ from previously reported patient groups in that we selected two groups for which abnormalities of white matter were either minimal or very severe. In addition, the patients were moderately to severely demented. Although we sought to select patients with maximal differences in abnormalities of white matter in the hope of finding clinical charac- 
teristics specific to these abnormalities, it could be that subtle neuropsychological differences are present when the dementia is mild, but are overwhelmed by the Alzheimer's disease process as the dementia progresses. Significant group differences in neuropsychological scores related to the presence of abnormalities of white matter, therefore, may not have been seen due to the moderate to severe degree of cognitive impairment in our patients. Small group size could have also limited our results. Consistent with previous data, ${ }^{18}$ the DAT + patients had generally lower neuropsychological test scores than the DAT - patients. Larger sample sizes would have given us the statistical power necessary to more accurately ascertain whether these differences were truly significant under the conditions tested.

We were, however, most interested in the relation between neuropsychological performance and cerebral metabolism among the DAT - and DAT + groups. The pattern of neocortical glucose metabolism was significantly different between the two dementia groups; however, as noted, both groups had a generally equal degree of dementia severity. This suggests that dysfunction of different brain regions may underlie the cognitive deficits among the two groups. Previous reports $^{14} 5253$ have shown significant relations between cerebral metabolism in the association neocortices and numerous neuropsychological tasks in patients with Alzheimer's disease. Using the $\mathrm{AD}$ ratio reported by Mielke et $a l,{ }^{53}$ we duplicated the previously reported significant correlation between neuropsychological performance and metabolism for the DAT - group, but not the DAT + group. Multivariate analyses of the relation between the $A D$ ratio and neuropsychological test scores for the two dementia groups also showed significant between group differences on one neuropsychological task, and a trend toward significance for three others which was not explained by the confounding effects of age, sex, and education. Although the interaction was significant only on one neuropsychological measure, this particular task reflects memory and attentional processes which have been previously shown to be affected in healthy subjects with abnormalities of white matter. ${ }^{46}$ Given the trend toward significance in three additional cognitive tasks, larger patient groups might have disclosed more generalised differences in the relation between neocortical metabolism and neuropsychological tests.

Wallerian degeneration of cortical neurons caused by Alzheimer's disease has been one hypothesis proposed to explain the increased prevalence of abnormalities of white matter in patients with Alzheimer's disease.$^{60}$ If neuronal cell death and subsequent Wallerian degeneration of axons was the sole cause of abnormalities of white matter in Alzheimer's disease, we would expect to see greater cerebral atrophy in the DAT + group when compared by dementia severity. Or, if not mean differences in cerebral volume, differences in the relation between severity of dementia and cerebral volume in patients with DAT + . We found neither. Not only were the group mean volumes nearly identical, but the relation between cerebral volume and severity of dementia was the same for both groups. Non-demented subjects with abnormalities of white matter have significantly greater cerebral atrophy, however, suggesting that these abnormalities are associated with tissue loss. ${ }^{6-9}$ The volume of tissue loss associated with abnormalities of white matter, although significant, is relatively small (about $3.0 \%$ in one study ${ }^{6}$ ). Tissue loss caused by Alzheimer's disease is greater than the tissue loss due to abnormalities of white matter, ${ }^{15}$ and may therefore obscure group differences in brain volume caused by abnormalities of white matter in the DAT + group.

Our data, however, do mitigate against the notion that abnormalities of white matter are the inevitable consequence of Alzheimer's disease. Members of both the DAT + and DAT - groups spanned the entire range of severity of dementia, including patients with minimal to severe cerebral atrophy. In addition, five members of each dementia group have had pathological confirmation of Alzheimer's disease. Detailed analysis of cerebral vasculature, white matter, and grey matter in a subset of these patients ${ }^{61}$ showed the presence of severe cerebral amyloid angiopathy, myelin pallor, and astrocytosis without axon loss in the DAT + group, which was absent from the DAT - patients. These data suggest that a pathology additional to, or coincident with, the markers of Alzheimer's disease, ${ }^{34} 35$ such as cerebral amyloid angiopathy, or other processes known to cause abnormalities of white matter, such as hypertensive vasculopathy, ${ }^{1}$ are present in patients with Alzheimer's disease with severe abnormalities of white matter.

How abnormalities of white matter might affect cerebral metabolism and cognition was not considered in our study. One hypothesis proposes that abnormalities of white matter affect cerebral metabolism through impairment of long corticocortical neurons leading to a functional "disconnection". ${ }^{66263}$ Healthy subjects with large hyperintense lesions in white matter show significant reductions in frontal lobe glucose utilisation which has been attributed to damage to corticocortical axons passing through central cerebral white matter. ${ }^{6}$ A similar process could explain the metabolic pattern of the DAT + patients, in whom the prototypical temporal-parietal dysfunction of Alzheimer's disease is diminished, and a more generalised reduction of cerebral metabolism is seen instead. ${ }^{662}$ Dysfunction in brain regions outside the temporal and the parietal lobes, particularly in the frontal lobe, ${ }^{4643}$ might contribute to the cognitive impairment seen in the $\mathrm{DAT}+$ patient group, and is consistent with the clinical findings of less pronounced parietal lobe dysfunction in patients with Alzheimer's disease with abnormalities of white matter. ${ }^{20}$

Although the aetiology may be diverse (for example, aging, cerebral amyloid angiopathy, 
or hypertension), the presence of severe abnormalities of white matter in patients with dementia affects the pattern of cerebral metabolism of glucose and the relation between the Alzheimer's disease ratio and WMDQ scores. In this regard, DAT + patients seem to be a subgroup of Alzheimer's disease wherein abnormalities of white matter indicate another concurrent pathological process. The clinical and research implications are unclear at this time, but further studies might elucidate these differences.

We thank Dr Vladimir Hachinski, Dr Bruce Miller, and Dr John Bowler for their helpful comment

1 Awad IA, Spetzler RF, Hodak JA, et al. Incidental subcortica lesions identified on magnetic resonance imaging in the elderly. I. Correlation with age and cerebrovascular risk factors. Stroke 1986;17:1084-9.

2 Inzitari D, Diaz F, Fox AJ, et al. Vascular risk factors and leuko-araiosis. Arch Neurol 1987;44:42-7.

3 Steingart A, Hachinski VC, Lau C, et al Cognitive and neurologic findings in subjects with diffuse white matter lucencies on somputed tomographic scan. Arch Neurol 1987;44:36-9.

4 Boone KB, Miller BL, Lesser IM, Mehringer CM, et al Neuropsychological correlates of white-matter lesions in healthy elderly subjects. A threshold effect. Arch Neurol 1992;49:549-54

5 Ylikoski R, Ylikoski A, Erkinjuntti T, Sulkava R, Raininko $\mathrm{R}$, Tilvis $\mathrm{R}$. White matter changes in healthy elderly persons correlate with attention and speed of mental processing. Arch Neurol 1993;50:818-24.

6 DeCarli C, Murphy DGM, Tran M, Grady CL, et al. The effect of white matter hyperintensity volume on brain structure, cognitive performance and cerebral metabolism structure, cognitive performance and cerebral me
in 51 healthy adults. Neurology 1996 (in press).

7 Mirsen TR, Lee DH, Wong CJ, Diaz JF et al. Clinical correlates of white-matter changes on magnetic resonance lates of white-matter changes on magnetic resonance
imaging scans of the brain. Arch Neurol 1991;48:1015-21.

8 Sullivan P, Pary R, Telang F, et al. Risk factors for white matter changes detected by magnetic resonance imaging in the elderly. Stroke 1990;21:1424-8.

9 Kertesz A, Black SE, Tokar G, Benke T, et al. Periventricular and subcortical hyperintensities on magnetic resonance imaging. "Rims, caps and unidentified brigh objects". Arch Neurol 1988;45:404-8.

10 Herholz K, Heindel W, Rackl A, Neubauer I, et al. Regional cerebral blood flow in patients with leuko-araiosis and atherosclerotic carotid artery disease. Arch Neurol 1990;47:392-6.

11 De Reuck J, Decoo D, Strijckmans K, Lemahieu I. Does the severity of leukoaraiosis contribute to senile dementia? A comparative computerized and positron emission tomocomparative computerized and positron emis
graphic study. Eur Neurol 1992;32:199-205.

12 Meguro K, Hatazawa J, Yamaguchi T, et al. Cerebral circulation and oxygen metabolism associated with subclinical periventricular hyperintensity as shown by magnetic resonance imaging. Ann Neurol 1990;28:378-83.

13 Masdeu JC, Wolfson L, Lantos G, et al. Brain white-matter changes in the elderly prone to falling. Arch Neurol 1989, 46:1292-6.

14 Haxby JV, Grady CL, Koss E, et al. Heterogeneous anteriorposterior metabolic patterns in Alzheimer's type dementia. Neurology 1988;38:1853-63.

15 Murphy DGM, DeCarli C, Daly E, Gillette JA, et al. Volumetric magnetic resonance imaging in men with dementia of the Alzheimer type: correlations with disease dementia of the Alzheimer type: correlation
severity. Biol Psychiatry 1993;34:612-21.

16 Roman GC. Senile dementia of the Binswanger type. A vascular form of dementia in the elderly. $¥ A M A$ cular form of

17 Chui HC. Dementia: a review emphasizing clinicopathologic correlation and brain-behavior relationships. Arch Neurol 1989;46:806-14

18 Diaz JF, Merskey H, Hachinski VC, Lee VC, et al. Improved recognition of leukoaraiosis and cognitive impairment
in Alzheimer's disease. Arch Neurol 1991;48: $1022-5$

19 Bondareff W, Raval J, Colletti PM, Hauser DL. Quantitative magnetic resonance imaging and the severity of dementia in Alzheimer's disease. Am f Psychiatry 1988;145:853-6.

20 Blennow K, Wallin A, Uhlemann C, Gottfries CG, et al. White-matter lesions on CT in Alzheimer patients: relation to clinical symptomatology and vascular factors. Acta Neurol Scand 1991;83:187-93.

21 Kertesz A, Polk M, Carr T. Cognition and white matter changes on magnetic resonance imaging in dementia. Arch Neurol 1990;47:387-91.

22 Yao H, Sadoshima S, Ibayashi S, Kuwabara Y, Ichiya Y, Fujishima $M$. Leukoaraiosis and dementia in hypertensive patients. Stroke 1992;23:1673-7.

23 Erkinjuntti T, Sulkava R, Palo J, Ketonen L. White matter low attenuation on CT in Alzheimer's disease. Arch Gerontol Geriatr 1989;8:95-104.

24 Scheltens PH, Barkhof F, Valk J, Algra PR, et al. White matter lesions on magnetic resonance imaging in clinically diagnosed Alzheimer's disease. Brain 1992;115:735 48

25 Gray R, Dubas F, Roullet E, Escourolle R. Leukoencephalopathy in diffuse hemorrhagic cerebral amyloid angiopathy. Ann Neurol 1985;18:54-9.

26 Haan J, Algra PR, Roos RAC. Hereditary cerebral hemorrhage with amyloidosis - Dutch type. Clinical and computed tomographic analysis of 24 cases. Arch Neurol 1990;47:649-53.

27 Leys D, Stoetaert G, Petit H, Fauquette A, Pruvo JP, Steinling $M$. Periventricular and white matter magnetic resonance imaging hyperintensities do not differ between Alzheimer's disease and normal aging. Arch Neurol 1990; 47:524-7.

28 Kozachuk WE, DeCarli C, Schapiro MB, Wagner EE, Rapoport SI, Horwitz B. White matter hyperintensities in Rapoport SI, Horwitz B. White matter hyperintensities in
dementia of the Alzheimer's type and in healthy subjects dementia of the Alzheimer's type and in healthy subjects without cerebrovascular risk factors. A magnetic
nance imaging study. Arch Neurol 1990;47:1306-10.

29 DeCarli C, Grady CL, Clark CM, Gouras G, et al. Imaging techniques and neuropsychological testing in dementia with severe white matter changes. In Hartmann A, Kuschinsky W, Hoye S, eds. Cerebral ischemia and dementia. Berlin: Springer-Verlag, 1991: 276-84.

30 Schwartz M, Creasey H, Grady CL, et al. CT analysis of brain morphometrics in 30 healthy men, aged 21 to 81 years. Ann Neurol 1985;17:146-57.

31 McKhann G, Drachman D, Folstein MF, et al. Clinical diagnosis of Alzheimer's disease: Report of the NINCDSADRDA work group under the auspices of Department of Health and Human Services Task Force on Alzheimer's disease. Neurology. 1984;34:939 44.

32 Folstein MF, Folstein SE, McHugh PR. "Mini-mental state": a practical method for grading the cognitive state of patients for the clinician. I Psychiatr Res 1975;12:189-98.

33 Hachinski VC, Iliff LD, Zilkha E, et al. Cerebral blood flow in dementia. Arch Neurol 1975;32:632-7.

34 Khachaturian ZS. Diagnosis of Alzheimer's disease. Arch Neurol 1985;42:1097-104

35 Mirra SS, Heyman A, McKeel D, et al. The consortium to establish a registry for Alzheimer's disease (CERAD). Part II. Standardization of the neuropathologic assessment of Alzheimer's disease. Neurology 1991;41:479-86.

36 Hachinski VC, Potter P, Merskey H. Leuko-araiosis. Arch Neurol 1987;44:21-3.

37 Fazekas F, Chawluk JB, Alavi A, Hurtig HI, Zimmerman RA. MR signal abnormalities at $1.5 \mathrm{~T}$ in Alzheimer's dementia and normal aging. A7NR Am 7 Neuroradiol 1987;8:421-6.

38 Wechsler DA. Wechsler adult intelligence scale. New York: Psychological Corporation, 1955.

39 Benton AL, Van Allen MW. Test of facial recognition manual. Ames, Iowa: University of Iowa, 1973. (Neurosensory Center publication No 287.)

40 Kaplan E, Goodglass H, Weintrub S. Boston naming test (experimental version). Boston, MA: Boston VA Medical Center, 1976.

41 Haxby JV, Duara R, Grady Cl, Cutler NR, Rapoport SI. Relations between neuropsychological and cerebral metabolic asymmetries in early Alzheimer's disease. $₹$ Cereb Blood Flow Metab 1985;5:193-200.

42 Wechsler DA. A standardized memory scale for clinical use. $\mathscr{F}$ Psychol 1945;19:87-95.

43 Tupler LA, Coffey CE, Logue PE, Djang WT, Fagan SM. Neuropsychological importance of subcortical white matter hyperintensity. Arch Neurol 1992;49:1248-52.

44 Porteus SD. Porteus maze test: fifty years application. Palo Alto, CA: Pacific Books, 1965.

45 Golden CJ. The Stroop color and word test: a manual for clinical and experimental uses. Chicago, Ill: Stoelting; 1978 .

46 Reitan RM. Validity of the trail making test as an indicator of organic brain damage. Percept Mot Skills 1958;8:271-6.

47 DeCarli C, Maisog J, Murphy DGM, Teichberg D, Rapoport SI, Horwitz B. Method for quantification of brain, central and peripheral CSF volumes from magnetic resonance images. F Comput Assist Tomog 1992;16: $274-84$.

48 Murphy DGM, DeCarli C, Schapiro MB, Rapoport SI, Horwitz B. Age-related differences in volumes of subcortical nuclei, brain matter, and cerebrospinal fluid in healthy men as measured with magnetic resonance imaging. Arch Neurol 1992;49:839-45.

49 Brinkman SD, Sarwar M, Levin HS, et al. Quantitative indexes of computed tomography in dementia and normal aging. Radiology 1981;138:89-92.

50 Brooks RA. Alternative formula for glucose utilization using labeled deoxyglucose. I Nucl Med 1982;23:538-9.

51 Sokoloff L, Reivich M, Kennedy C et al. ["C]-deoxyglucose method for the measurement of local cerebral glucose utilization: theory, procedure, and normal values in the conscious and anesthetized albino rat. $\mathcal{f}$ Neurochem 1977 28:8897-916.

52 Grady CL, Haxby JV, Schapiro MB, Gonzales-Aviles A, Kumar A, et al. Subgroups in dementia of the Alzheimer type identified using positron emission to

53 Mielke R, Herholz K, Grond M, Kessler J, Heiss WD. Severity of vascular dementia is related to volume of metabolically impaired tissue. Arch Neurol 1992;49: metabolical

54 SAS Institute. SAS version 6.3. Cary, NC: SAS Institute, 1990.

55 Kleinbaum DG, Kupper LL, Muller KE, eds. Applied regression analysis and other multivariable methods: Boston: PWS-KENT Publishing Company, 1988:297-313. 
56 Lezak MD. Neuropsychological assessment: New York: Oxford University Press, 1976

57 Hatazawa J, Yamaguchi T, Ito $M$, Yamaura $H$, Matsuzawa $T$. Association of hypertension with increased atrophy of brain matter in the elderly. $\mathcal{F} \mathrm{Am}$ Geriatr Soc 1984;32: 370-4.

58 Salerno JA, Murphy DGM, Horwitz B, et al. Brain atrophy in older hypertensive men: a volumetric magnetic resonance study. Hypertension 1992;20:340-8.

59 Mentis MJ, Salerno J, Horwitz B, et al. Reduction of functional neuronal connectivity in long-term treated hypertional neuronal connectivity in

60 Leys D, Pruvo JP, Parent M, et al. Could Wallerian degen- eration contribute to "leuko-araiosis" in subjects free of any vascular disorder? $\mathcal{f}$ Neurol Neurosurg Psychiatry 1991;54:46-50.

61 DeCarli C, Brady D, Katz D, Alston SR, Burger P, et al. Neuropathological findings in Alzheimer's disease with severe leukoencephalopathy. Neurology 1994;44(suppl2): A370-A371.

62 Yao H, Sadoshima S, Kuwabara Y, Ichiya Y, Fujishima M. Cerebral blood flow and oxygen metabolism in patients with vascular dementia of the Binswanger type. Stroke with vascular dem

63 Scheinberg P. Dementia due to vascular disease: a multifactorial disorder. Stroke 1988;19:1291-9.

\section{Baron Constantin von Economo and encephalitis lethargica}

Although younger neurologists may not have encountered postencephalitic parkinsonism, encephalitis lethargica merits mention in contemporary reviews of Parkinson's disease. The name of von Economo is inseparably and justifiably attached to the disease since his was the major description ${ }^{1}$ of an illness that raged in epidemic form in Europe and North America between 1916 and 1926. Ivy McKenzie provided a scholarly account of the illness in Glasgow. ${ }^{2}$ Longer texts were written by Jelliffe, ${ }^{3}$ and by Wimmer. ${ }^{4}$ At first, others confused encephalitis lethargica with the pandemic of influenza (Spanish grippe). Cruchet had first noted encephalitis lethargica in the winter of 1915-16 in French soldiers in Verdun, ${ }^{5}$ and a few cases were seen in the spring of 1915 in Rumania.

von Economo published 27 papers including a book $^{6}$ on encephalitis lethargica.

\section{Excerpts from a translation of his classic descrip- tion ${ }^{1}$}

"We are dealing with a kind of sleeping sickness, having an unusually prolonged course. The first symptoms are usually acute, with headaches and malaise. Then a state of somnolence appears, often associated with active delirium from which the patient can be awakened easily. $\mathrm{He}$ is able to give appropriate answers, and to comprehend the situation. This delirious somnolence can lead to death, rapidly, or over the course of a few weeks. On the other hand it can persist unchanged for weeks or even months with periods lasting hours or days or even longer, of fluctuation of the depth of unconsciousness extending from simple sleepiness to deepest stupor or coma .... During the first days of the illness, isolated signs of meningeal irritation appear.... The appearance of fever and its intensity do not seem to have any effect upon the course and signs of the disease....

As a rule these general symptoms are joined by paralysis of the cranial nerves as well as in the extremities ... a paralytic ptosis often combined with partial or total paralysis of other branches of the oculomotor nerve .... Paresis of the other cranial nerves and paralysis of the extremities with reflex disturbances can occur also"

[seven case reports and an account of the clinical features are then given] ....

"The spinal fluid ... showed increased pressure at the beginning; it later decreased in spite of persistent somnolence. The total protein was below the normal upper limit; ... In case 1,43 cells $/ \mathrm{mm}^{3}$, in case 2,19 cells $/ \mathrm{mm}^{3} \ldots$ strong predominance of polymorphonuclear leukocytes. Repeated examina- tions for microorganisms was negative in every case. The Wassermann reaction in serum and spinal fluid was always negative ....

As the residual of such a paresis (upper and lower extremities), spasms, increased reflexes, or the Babinski phenomenon can persist for a long time, even after the ocular muscle paralysis and somnolence have receded ... one often finds a peculiar rigidity of the extremities (cases 1,2 and 4). Like most of the signs this rigidity disappears later ... We frequency find (cases $1,2,3,4,7$ ) ataxic disturbances that make one think of involvement of the cerebellum. Case 7 demonstrated severe ataxic tremor .... With reference to pontine encephalitis I describe briefly several cases seen in the emergency room during the same period"

[six further case reports and a long discussion on differential diagnosis and pathology follow] ...

von Economo concludes: "Therefore we have the histological picture of a polioencephalitis cerebri, pontis et medullae oblongatae, with a slight poliomyelitis of a perivascular, inflammatory and diffusely infiltrative but not haemorrhagic and only slightly neuronophagic character."

Born in Braila, Rumania, of an aristocratic Greek family he studied engineering before reading medicine in Vienna. Early training was with Nothnagel, Pierre Marie, and Kraepelin before he returned to the psychiatric clinic in Vienna.

His work centred on neuroanatomy, head injuries in the first world war, and investigations on sleep, cortical architecture, and on Wilson's disease.

$\mathrm{He}$ married the daughter of Prince Alois von Schönburg-Hartenstein, and being of independent means, rejected the chair of psychiatry on von Jauregg's retirement in 1928 . He died suddenly of heart disease in 1931 .

\section{J M S PEARCE 304 Beverley Road, Anlaby, Hull HU10 $7 B G, U K$}

1 von Economo C. Encephalitis lethargica. Wien Klin Wschr 1917;30:581-5 (for full text of translation see Wilkins RH, Brody IA. Encephalitis lethargica. Arch Neurol 1968;18:324-8)

2 McKenzie I. Discussion of epidemic encephalitis. Epidemiological considerations. $B M \mathcal{F} 1927 ; 1: 532-4$.

3 Jelliffe SE. Post-encephalitic respiratory disorders. New York: Nervous and Mental Disease Publishing Company, 1927.

4 Wimmer SA. Chronic epidemic encephalitis. London: Heinemann, 1924

5 Cruchet $R$. The relation of paralysis agitans to the parkinsonian syndrome of epidemic encephalitis. Lancet 1927; i: 264 .

6 von Economo C. Encephalitis lethargica: its sequelae and treatment (KO Newman's translation of Die Encephalitis, Wien 1929). London: Oxford University Press, 1931. 